\title{
Erratum to: Contested Childhoods: Growing up in Migrancy
}

\author{
Marie Louise Seeberg and Elżbieta M. Goździak
}

\section{M.L. Seeberg and E.M. Goździak (eds.), Contested Childhoods: Growing up in Migrancy, IMISCOE Research Series, DOI 10.1007/978-3-319-44610-3}

This book was inadvertently published with the incorrect license type CC BY 4.0. This has now been amended throughout the book to the correct license type CC BY-NC 2.5.

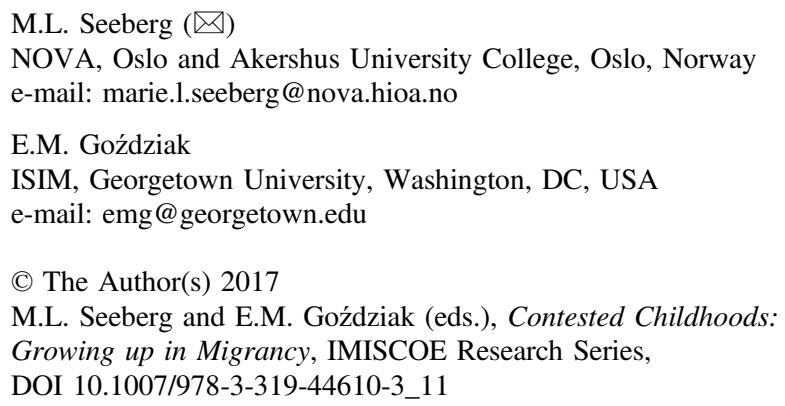

